\title{
El movimiento estudiantil de La Plata en los años '50: reformismo, peronismo y Guerra Fría a través de una década
}

\section{The Student Movement (of La Plata) in the 50s: Reformism, Peronism and Cold War through a decade}

\author{
Nayla Pis Diez \\ Centro de Investigaciones Socio Históricas; \\ Instituto de Investigaciones en Humanidades y Ciencias Sociales; \\ Consejo Nacional de Investigaciones Científicas y Técnicas; \\ Universidad Nacional de La Plata (Argentina) \\ nayla.pdiez@gmail.com
}

\begin{abstract}
Resumen
Este artículo propone una reconstrucción de la historia del movimiento estudiantil de la Universidad de La Plata, en la década de 1950. Abordaremos los cambios y rupturas que atravesó el estudiantado reformista de aquella ciudad durante diez años que contuvieron, sin dudas, dos etapas históricas bien diferenciadas. Por ello, se busca observar rupturas y continuidades considerando dos planos de análisis: sus definiciones respecto de la universidad, la Reforma Universitaria y sus banderas gremiales; y la forma cómo aparecen las coordenadas del debate político de la década, peronismo/antiperonismo, también comunismo/anticomunismo y democracia/totalitarismo.
\end{abstract}

Palabras clave

Reformismo; Movimiento Estudiantil; La Plata; Peronismo; Guerra Fría.

\begin{abstract}
This article reconstructs the history of the Student Movement of the University of La Plata, in the 1950s. We will address the changes and ruptures that the Reformist Student of that city went through for ten years that contained two historical stages. Therefore, our aim is to observe ruptures and continuities considering two levels of analysis. First, their definitions regarding the university, the University Reform and their union flags. Second, how the coordinates of the political discussion of the stage appeared (Peronism / antiPeronism, also communism / anti-communism and democracy / totalitarianism).
\end{abstract}

\section{Keywords}

Reformism; Student Movement; La Plata city; Peronism; Cold War. 


\section{Nayla Pis Diez}

\section{Introducción}

Este artículo propone una reconstrucción de la historia del movimiento estudiantil de la Universidad de La Plata, en la década de 1950. Abordaremos los cambios y rupturas que atravesó el estudiantado reformista de aquella ciudad durante diez años que contuvieron, sin dudas, dos etapas históricas bien diferenciadas: los últimos años del segundo gobierno peronista; y, a partir de 1955, los primeros del posperonismo (el régimen militar de la Revolución Libertadora y el gobierno del radical Arturo Frondizi). En ambas encontramos, no solo dos momentos políticos del país casi opuestos, sino también realidades universitarias completamente distintas, con normativas y un funcionamiento interno casi excluyentes entre sí Como sabemos, durante los primeros años de la década, las posturas de una buena parte de los grupos estudiantiles identificados con la Reforma Universitaria fue de oposición al gobierno peronista. Y en este lugar político el reformismo asumió, primero, los reclamos históricos que lo enfrentaban directamente con el modelo peronista de universidad: la participación política y el auto gobierno, en un contexto de prohibición y persecución de la militancia reformista.

En segundo lugar, otros elementos propios del período nos hablan también de una politización específica que el reformismo de la UNLP atravesó por entonces. Así, su sector mayoritario mantuvo una inscripción en la lucha contra el fascismo, en Argentina y el mundo; en el anticomunismo, acentuado con el correr de los años '50; y una concepción de su tarea opositora como una suerte de batalla nacional, que había tenido sus primeros capítulos en Mayo de 1810 y la Batalla de Caseros. Estos elementos pueden pensarse como una cara y otra de una misma postura inserta en la lógica política e ideológica de la Guerra Fría, que incluía además una consecuente valorización de la democracia liberal; y, cabe decirlo, la exclusión de otros actores reformistas como los comunistas. Ahora bien, mediando la década, y tras un cambio de régimen político dado por la maniobra militar que derrocó al gobierno de Juan D. Perón, aquellos elementos comenzaron a moverse.

Nos proponemos realizar una lectura de largo plazo sobre la politización del actor movimiento estudiantil, en este caso, el identificado con la Reforma Universitaria y radicado en la Universidad Nacional de La Plata (UNLP). Las fuentes utilizadas son fundamentalmente escritas: los diarios platenses (El Argentino, en particular) y los documentos elaborados por la Dirección de Inteligencia de la Provincia de Buenos Aires (DIPBA), hoy desclasificados por la Comisión Provincial por la Memoria (CPM). Si bien el contenido general de estas páginas estará dado por la reconstrucción de acciones, discursos y posiciones en escenarios determinados, debemos decir que nos guía también una intención analítica. Repasar una década entera de nuestra historia argentina, con momentos políticos bien diferenciados nos permite indagar en, justamente, la relación entre la vida interna del movimiento estudiantil y ese "contexto", del cual también fue indudable protagonista. ¿Cómo explicamos las posiciones estudiantiles en tal o cual etapa política? ¿Qué nos permite explicar el "adentro" universitario y qué los sucesos de la vida nacional? Por ejemplo, ¿cómo 


\section{El movimiento estudiantil de La Plata en los años '50: reformismo, peronismo y Guerra Fría a través de una década}

comprendemos el "antiperonismo" del sector universitario reformista? iY el posterior abandono de esa postura?

\section{La pregunta por la política, la politización y la universidad}

Debe decirse que los interrogantes arriba planteados no son nuevos en el campo de estudios sobre el movimiento estudiantil. Durante las décadas de 1950-1970 no fue escaso el número de producciones dedicadas a un actor que estaba marcando la política de diversos países del mundo occidental. Algunos trabajos ponderaron el concepto de "generación", otros resaltaron la importancia de las estructuras universitarias del período, sin dudas, atravesadas por fuertes cambios. Desde otras lecturas se entendía que todo aquello debía ponderarse con el marco social en el cual un movimiento estudiantil coloca sus demandas, se moviliza y adquiere proyección. Por ejemplo, una propuesta de este tipo ha sido la elaborada por el argentino Jorge Graciarena, quien parte del hecho de que no puede pensarse a los movimientos estudiantiles de forma aislada. Más bien, todo análisis sobre el movimiento estudiantil debe ser relacional, es decir, debe considerarlo como un actor político más en las disputas de la sociedad de la que es parte.

En nuestro país, durante las décadas de 1980 y 1990 este debate resurgió de la mano de obras que abordaron la relación entre la política y ciertos campos específicos de actuación (el cultural, universitario e intelectual) en los años '60 y '70. No fue menor su aporte, pues estudios como los de Oscar Terán y Silvia Sigal se constituyeron una suerte de "lente" o punto de partida para pensar aquella parte de la historia. Sin embargo, hay cuestiones para retomar y revisar. Para Sigal (1991) una de las características de la vida universitaria argentina habría radicado en su definición cual terreno propio de conflictos, con reglas específicas y definidos casi exclusivamente en función de la Reforma. Desde aquí, las diferencias correspondientes al espacio ideológico nacional (entre, por ejemplo, socialistas, comunistas o radicales) correspondían a un "afuera" bien separado del "adentro reformista" (p.71). Estas consideraciones nos otorgan una lectura tanto sobre las características del movimiento estudiantil argentino, como también una forma de comprender la historia reciente, pues:

\footnotetext{
"Lo que había otorgado su fuerza singular al movimiento estudiantil argentino fue, precisamente, enunciar una concepción de la sociedad exclusivamente desde el particularismo universitario. Durante los años de politización universitaria, desde mediados de los 60 hasta 1976, ni la institución ni la Reforma serán ya productora de identidad, y los partidos se encargarán de canalizar los conflictos estudiantiles" (Sigal, 1991, p. 71).
}

Hay algunos elementos a revisar aquí: primero, basarse sin grises en la idea de "particularismo universitario" puede llevarnos a desconocer la existencia no solo de debates intra reformistas muy fuertes sino también la presencia de militancia 
política y partidaria que no leía la realidad nacional solo desde su condición de estudiante. Por otra parte, la politización del estudiantado no solo es anterior al período que se señala, sino que es un dato constante en la historia del movimiento universitario argentino. Esto no quiere decir que los debates universitarios o gremiales, o más aún las elecciones en los Centros de Estudiantes, no hayan importado. Tampoco que la lógica y definiciones de los partidos fuera predominante, incluso es falso pensar que las agrupaciones respondían totalmente a ellas. El punto es que, si no se consideran las características de esa tensión, hay una parte de la dinámica estudiantil que no se puede explicar. Así, la delimitación tajante entre "lo político" y "lo universitario" debe repensarse a la luz de las coyunturas históricas. Pues, por caso, sí bien es cierto que durante 1945-1955 encontramos un reformismo más bien unido en su antiperonismo y en las defensas de sus banderas clásicas, ya a fines de la década de 1950 el reformismo no producirá un "nosotros" ni una identidad común pues las distancias ideológicas (y también partidarias) lo atravesarán completamente.

¿Cómo pensamos entonces la historia del movimiento estudiantil reformista argentino? ¿Qué hace que el movimiento estudiantil de una misma universidad presente, en distintos momentos históricos, diferentes objetivos, banderas y acciones? Desde esta óptica, el concepto de politización nos sirve para pensar aquellas cuestiones, en tanto alude a un proceso a través del cual las reivindicaciones y las prácticas de un campo específico (en este caso, el universitario y estudiantil) pasan a definirse como parte de un proyecto político global, sea del carácter que sea (reaccionario, liberal, peronista, antiperonista o socialista). De esta manera, un interés creciente por la lucha política se articula con (o en algunos casos, acaba subsumiendo) la lucha sectorial o corporativa, con contenidos, discursos y acciones propias del momento en que esa articulación adquiere forma. En estas páginas, observaremos rupturas y continuidades considerando dos planos de análisis: sus definiciones respecto de la universidad, la Reforma Universitaria y sus banderas; y la forma cómo aparecen las coordenadas del debate político de la década, peronismo/antiperonismo, también comunismo/anticomunismo y democracia/totalitarismo. En síntesis, buscaremos indagar en la politización de aquel actor, ordenando las formas como lograron articular la lucha gremial (corporativa o estudiantil), la identidad reformista y las posiciones políticas y adscripciones partidarias.

\section{La política de los años '50: peronismo, Guerra Fría y dinámicas internas}

Durante los años de gobiernos peronistas, la postura del movimiento reformista (y aquí podemos incluir a intelectuales y profesores identificados con él) fue de férrea oposición. Trabajados abocados a su reconstrucción, nos indican que algunos elementos que nos permiten comprenderla son de índole internacional, pues nos encontramos con una escena marcada por la dicotomía democracia/fascismo a 


\section{El movimiento estudiantil de La Plata en los años '50: reformismo, peronismo y Guerra Fría a través de una década}

partir de la cual los reformistas (y muchos otros actores, como los partidos políticos de izquierda y el radicalismo) entendieron al peronismo, ubicándolo como caso nacional del segundo fenómeno (Graciano, 2005; Califa, 2014; Pis Diez, 2018). En este marco, todas las políticas universitarias del peronismo fueron no solo rechazadas por antirreformistas, sino también directamente identificadas con un modelo autoritario de universidad. Es que medidas como las intervenciones universitarias, las designaciones de autoridades antirreformistas y las ilegalizaciones de organismos estudiantiles, operaron como elementos concretos que apuntalaron aquella lectura. Tal como ha dicho Graciarena (1971), durante los años ' 40 y hasta 1955, la mayor parte del reformismo universitario fue un actor político enfrentado al gobierno y una pieza fundamental del bloque conformado por partidos como la Unión Cívica Radical (UCR) y el Partido Socialista (PS).

En 1955, con el derrocamiento del peronismo, se abre una nueva etapa en el país y también en el mapa estudiantil. Un inicial apoyo al gobierno militar derivó, al año siguiente, en grietas, debates internos y el posterior surgimiento de un sector reformista (platense y nacional) crítico de la "Revolución Libertadora" y "tolerante" respecto del peronismo. Sin dudas, todo ello no se entiende sin colocar sobre la mesa los intentos oficiales de aprobar una normativa de orden interno de las universidades, que incluía muchos elementos rechazados por los reformistas, entre ellos, el famoso Artículo n. ${ }^{\circ}$ 28. No obstante, la ruptura nacional de la UCR, los debates internos del Socialismo y los cambios de posturas en el Partido Comunista (PC) ayudan también a comprender tales desplazamientos en el reformismo. Ya veremos cómo.

Pero cabe decir algo más, central para nuestro análisis. Ya desde fines de 1940, el movimiento estudiantil estaba marcado por otro tipo de disidencias: aquellas insertas en la lógica de la Guerra Fría pero atravesadas y resignificadas en función de importantes elementos locales, como fueran, la Reforma Universitaria, el nacionalismo y el peronismo/antiperonismo. Como nos indican estudios recientes (Rey Tristán, 2012; Marchesi, 2017), en el campo de estudios sobre la Guerra Fría en América Latina ha comenzado a ganar lugar una perspectiva atenta a los factores internos (políticos, históricos, culturales) que habrían dado forma a un impacto nacional y particular de aquella contienda global. Diversas obras proponen volver sobre la polarización peronismo/antiperonismo y su inscripción en la dinámica de la Guerra Fría y de un anticomunismo con larga historia en nuestro país. Por ejemplo, para Marina Franco (2019) el anticomunismo fue un componente central de la construcción ideológica inicial del peronismo en los ' 40 , junto al nacionalismo $\mathrm{y}$, al antiliberalismo. Pero también, el anticomunismo fue un componente central de los sectores liberales antiperonistas durante los años '50, llegando a marcar a los gobiernos post 1955 así como también, agregamos, el accionar y los discursos de actores repartidos en diversos ámbitos (como los partidos políticos y una parte del movimiento estudiantil).

Como veremos en las páginas que siguen, en los inicios de 1950, un sector mayoritario del reformismo de la UNLP cuajó con el anticomunismo y el 
antiperonismo en torno a dos banderas claves: la defensa de la libertad y la crítica a los totalitarismos. De acuerdo a Valeria Galván (2018), la asociación del peronismo al mapa de los totalitarismos del siglo $\mathrm{XX}$, en el que también estaban los comunismos, favoreció el solapamiento entre el antiperonismo y el anticomunismo. Y, agregamos, hacia fines de los ' 50 , esto no hizo más que profundizarse con un evento continental de envergadura como fue la Revolución Cubana. Pero para entonces, esas posturas dejarían de ser mayoritarias en el estudiantado.

\section{Una reconstrucción desde la ciudad de La Plata}

\section{El reformismo en la oposición: antiperonismo y anticomunismo van de la mano} (1949-1955)

En la Universidad de La Plata, a comienzos de 1948 asumió como interventor Carlos Rivas, inaugurando un período que va a extenderse hasta el año 1954, con diversas autoridades pero con una serie de características comunes que se mantenían en torno a la consolidación de las políticas universitarias peronistas. Por un lado, con Rivas, se instaló en la universidad platense un clima de "optimismo", normalidad y "compenetración con la Doctrina Peronista" cuya base era más bien una suerte de derrota del cuerpo universitario opositor, más o menos lograda en los años anteriores. La Ley Universitaria n. $\stackrel{0}{13.031}$ plasmó una serie de transformaciones institucionales que desarmaron importantes conquistas reformistas (la participación estudiantil en el gobierno, por ejemplo) en un contexto en que la situación del movimiento estudiantil reformista era, desde 1946, de desmovilización y aislamiento debido a la clausura de los centros estudiantiles y la prohibición de las reuniones políticas. Pero de la misma manera, tuvieron lugar diversas normativas que hacían a lo que hemos denominado la democratización social de la universidad: la política de becas y luego, la supresión de los aranceles; en la UNLP, las creaciones del Comedor Universitario en 1949 y del Departamento de Acción Social (1948), entre otros.

No obstante, la oposición del estudiantado reformista hacia la política universitaria peronista no tenía grises. Buena parte de los militantes reformistas de la UNLP pertenecían, adherían o simpatizaban con la UCR, el PS y el PC; luego y en menor medida, con el anarquismo y el trotskismo. Estas orientaciones nacionales nos marcan dos corrientes reformistas que de acuerdo a la coyuntura y a dichas orientaciones, actuaron o no en conjunto. Por un lado, la conformada por militantes de la Federación Juvenil Comunista (FJC) y adherentes, con presencia en seis Facultades de un total de ocho y referentes como Otto Vargas Jorge Braindwaiman y Jaime Gluzmann. Luego, las agrupaciones constituidas por estudiantes independientes, radicales, socialistas, anarquistas de la Unión Socialista Libertaria de La Plata y en menor medida, trotskistas del Grupo Obrero Marxista. Mayoritario en todas las facultades, este segundo espacio dirigió la FULP durante toda la década 


\section{El movimiento estudiantil de La Plata en los años '50: reformismo, peronismo y Guerra Fría a través de una década}

peronista en convivencia con los comunistas. Hasta los primeros años cincuenta, ambas líneas competían en los Centros y en la FULP. En la ciudad de La Plata, 1949 dio señales de una incipiente reactivación, pues frente a una serie de conflictos sindicales, los jóvenes universitarios prestaron su apoyo a quienes aparecían como eventuales aliados en la oposición, los huelguistas gráficos de 1949, los marítimos en 1950 o los ferroviarios en 1951.

En junio de 1950, una FULP presidida por Alfredo Eric Calcagno y Oscar Valdovinos, organizó el típico acto de homenaje a la Reforma Universitaria. Este, que contó con alrededor de 200 asistentes y la colocación de una simbólica corona fúnebre en homenaje "a los caídos de la Reforma", acabó en corridas, enfrentamientos con las fuerzas policiales y en la detención de dos estudiantes. Pero también encontramos en este acto indicios de la disputa que va a marcar al movimiento reformista de estos primeros años cincuenta. Relata Bernardo Kleiner (1964) que el discurso central, a cargo de la dirigencia de la FULP, tuvo un marcado tono antiperonista provocando la refutación pública del estudiante comunista Otto Vargas, quien llamó a la unidad estudiantil con "ese pueblo" que el otro criticó por su apoyo al presidente Juan Perón (p.101). Por esta refriega, en la siguiente reunión de la FULP se propuso la expulsión de Vargas.

Para comprender el episodio de junio de 1950, debemos remitirnos a unos años antes. Como bien ha reconstruido María Estela Spinelli (2005), la posición del comunismo frente al régimen de 1943 fue de radical oposición, caracterizándolo además como una "dictadura militar nazi fascista" con intereses oligárquicos e imperialistas. La participación en el frente electoral de 1946 encuentra razones en dicho diagnóstico, dado por el enfrentamiento de la democracia contra el nazismo, ubicándose ellos bajo la primera bandera. Pero, a diferencia de otros sectores antiperonistas, el PC comenzó a elaborar una visión más compleja del fenómeno que se expresó en el análisis crítico de la derrota electoral de febrero de 1946, el reconocimiento del apoyo obrero hacia Juan D. Perón y en un proceso de revisión de su línea política. Así las cosas, en el mundo universitario los comunistas quedaron enfrentados a aquellos núcleos del reformismo que mantuvieron la línea de oposición intransigente hacia el gobierno. Pero hay algo más, al factor nacional (las posiciones frente al peronismo) debe sumarse un contexto internacional ya no sumido en la "guerra mundial" contra el fascismo sino en la Guerra Fría y el enfrentamiento entre los antes aliados. Además de la persistente oposición al peronismo y de la cambiante posición comunista, este elemento internacional nos habla de un novedoso marco ideológico a partir del cual hacia 1950 socialistas y radicales adoptaron una postura anticomunista común. Las divergencias entre ambas tendencias del reformismo se harán insalvables mediando el año 1952.

Ese año, tuvo lugar una maniobra de acercamiento por parte de los comunistas universitarios hacia la Confederación General Universitaria (CGU). La CGU había surgido hacia la segunda mitad del año 1950, con sus respectivas regionales, con importantes medios materiales a su favor y con un estatuto oficial de espíritu nacionalista, católico y anticomunista que manifestaba una adhesión plena a la 
Doctrina Peronista y una orientación dada por el objetivo de contrarrestar a una FUA defensora de "valores caducos", el liberalismo y el reformismo (Acha, 2011, p. 79). El 20 de septiembre de 1950 surgía la Federación Gremial Universitaria (FGU) de La Plata y en noviembre de 1950 se realizó el acto de lanzamiento nacional en el Teatro Colón de la ciudad de Buenos Aires.

Las entidades reformistas no tardaron en manifestar su desprecio hacia la creación de las gremiales peronistas, entendidas al mismo tiempo como competidoras y como espacios que no representaban realmente al estudiantado. Con mejores oportunidades políticas y mayor cantidad de recursos, la CGU era un rival insoslayable que iba desde el campo gremial y político hasta el terreno de la representación internacional.

Pocas cosas quedaban por fuera de las coordenadas políticas de entonces y, claro, no eran exclusivamente los reformistas quienes se ubicaban en ellas. Como ha observado Claudio Panella (2014), las páginas del periódico oficial de la organización (Actitud) se encontraban impregnadas de peronismo, nacionalismo y catolicismo militantes, pero también de un fuerte tono anticomunista, y muy especialmente los análisis sobre la política internacional. Esto no quedaba solo en las páginas de Actitud, sino que se proyectaba a las alianzas y las construcciones internacionales. Si los reformistas contaban con su Congreso Panamericano de Estudiantes, los peronistas de la CGU organizaron en 1952 el Congreso Mundial de la Juventud, del cual surgió la Organización Mundial Universitaria (OMU). Como encuentra Panella, es en la arena internacional dominada por la Guerra Fría, donde la CGU propició la creación de la OMU como entidad tercerista frente a la Unión Internacional de Estudiantes, de filiación comunista, y al Secretariado Coordinador de Uniones Nacionales de Estudiantes (CO-SEC), liberal y anticomunista, al cual estaba adherida la FUA.

Llamativamente, ni las caracterizaciones que el reformismo sostenía de la CGU, como tampoco el fuerte anticomunismo de esta, desalentaron a que, en 1952, una dirigencia temporal del PC ordenara a sus militantes el ingreso a los frentes estudiantiles del peronismo. De acuerdo a su impronta ideológica descripta, la CGU se negó a aceptarlos. El episodio finalizó a los pocos meses, cuando desde la dirigencia partidaria se desarticuló tal política de alianzas. No obstante su escasa efectividad, la decisión comunista fue duramente criticada por el resto de los grupos reformistas, quienes la calificaron directamente de traición. Como ha sido reconstruido (Pis Diez, 2018, p. 89 y ss.), en la UNLP un episodio particular de enfrentamientos con la CGU acabó en la detención de quince estudiantes de FULP y la deportación de dos de ellos, oriundos del Perú. Cuando la FULP acusó a la CGU por una supuesta responsabilidad en la última medida, los comunistas se posicionaron en favor de los peronistas. Por esto, algunos integrantes de las organizaciones comunistas de Ingeniería, Medicina y Química fueron expulsados de la Asamblea General de Centros de la FULP. Puede haber matizado posiciones el hecho de que, en nuestra ciudad, muchos militantes comunistas inicialmente se negaron al ingreso, retrasándolo e incluso impidiendo su concreción. 


\section{El movimiento estudiantil de La Plata en los años '50: reformismo, peronismo y Guerra Fría a través de una década}

A partir de aquí, la relación de los reformistas con los comunistas se tornó irreversiblemente conflictiva, quedando estos últimos cada vez más aislados y en decrecimiento. Pero al quedar en las direcciones de las Federaciones y en buena parte de los Centros un reformismo fervientemente antiperonista, una nueva etapa se abrió.

Desde 1953, la política estudiantil estuvo dominada por el rechazo a los Cursos de Formación y Cultura Argentina y la organización de campañas electorales en Córdoba, La Plata, Buenos Aires y Litoral. Mientras los estudiantes cordobeses denunciaban su objetivo de "impartir obligatoriamente propaganda política" contraria a los "tradicionales principios democráticos", la FULP manifestaba que "el estudiantado no reconoce a la Doctrina Nacional Peronista como ley nacional". La oposición de los grupos reformistas no logró interrumpir el desarrollo de los Cursos; frente a esto, las acciones opositoras se trasladaron al interior de las aulas, al debate en torno a los contenidos y las afirmaciones de los profesores. Según Kleiner (1964, pp. 134 y ss.) esta campaña fue una experiencia de lucha ideológica clave para el reformismo de entonces. Las principales disputas eran dadas contra el revisionismo histórico y la figura de Juan Manuel de Rosas y en defensa de los acontecimientos de mayo de 1810 y de la Batalla de Caseros. Favorece esta interpretación la campaña de la FUA contra la repatriación de los restos de Rosas. Afirmaba aquella en agosto de 1954:

\footnotetext{
"El revisionismo, hecho el clima a través de publicaciones y textos escolares, pretende reivindicar la figura trágica de Rosas y ensombrecer la memoria de quienes lucharon por el progreso y la organización institucional (...) Rosas es la antítesis de Mayo. Mayo es la eclosión del espíritu democrático y liberal (...) Solo pueden justificar a Rosas quienes pretenden exaltar el espíritu autoritario y liberticida en tiempo presente".
}

Encontramos elementos que nos hablan sí de una politización específica que el reformismo de la UNLP atravesó por entonces: su inscripción en la lucha contra el fascismo, en Argentina y el mundo; el anticomunismo, acentuado con el correr de los años '50; la concepción de su tarea opositora como una responsabilidad inscripta en una batalla histórica nacional contra el autoritarismo (representado antes por Rosas, ahora por Perón). Esto, en un contexto donde las posibilidades de reunión y de trabajo gremial era, para los Centros de Estudiantes y las organizaciones reformistas, casi nulo, debido a la prohibición y persecución de la militancia.

\section{El reformismo frente a la "Revolución Libertadora": antiperonismo y grietas internas (1955-1957)}

Finalizando septiembre de 1955, y en medio del golpe de Estado autodenominado Revolución Libertadora, todas las universidades fueron ocupadas. En el caso platense, lo fue por el mismo grupo de reformistas que había marcado el tono 
político de la UNLP entre las décadas de 1940 y 1950, y que ahora encontramos orientando su reorganización y desperonización. Así, un efímero gobierno fue compuesto por, entre otros, el socialista Emir Salvioli de Ingeniería, Eduardo Schaposnik (militante socialista y vicepresidente de la FUA en 1945), René Barbich (presidente de la FULP en 1951); y tres profesores, el radical Alfredo Calcagno y los libertarios Carlos Bianchi y Rafael Grindfeld. El espíritu general de la universidad era de triunfo y oportunidad, como afirma la FULP:

\begin{abstract}
"Como hecho simbólico señalamos que hoy nuestra universidad está en manos del gobierno estudiantil, provisoriamente. Después de un interregno de doce años de dictadura tiene hoy esta casa de estudios la oportunidad magnífica de (...) volver a las normas democráticas de vida, en la vigencia plena de la libertad; hacer de la cultura una auténtica expresión de la voluntad humana; señalar en ella los valores inapreciables del pensamiento libre y la conducta cívica frente a los demás hombres." (El Argentino, 30/09/1955).
\end{abstract}

Sin dudas, esta coyuntura representaba para los reformistas una oportunidad histórica de regresar a una universidad regida ahora por otros principios. Rápidamente comenzó en las facultades la "recuperación" de los gremios estudiantiles, es decir, el desmantelamiento de los organismos adheridos a una CGU y el reinicio de actividades públicas de los Centros reformistas adheridos a la FULP. Los organismos estudiantiles participaron además de la "desperonización" académica, que incluyó cesantías, separaciones o renuncias de al menos 270 docentes de diversa jerarquía (Pis Diez, 2018, p. 105). A la par, fueron realizados numerosos actos en los cuales sobresalieron declaraciones y posicionamientos sobre los temas del momento: la década pasada, la Reforma universitaria y la universidad "nueva". En los discursos de profesores, viejos militantes y dirigentes sobresalía una posición de corte liberal democrático, de fuerte énfasis en la defensa de las libertades políticas y la participación, que bien se amalgamó con la reivindicación de los principios reformistas, los mismos que vendrían a asegurar aquellas libertades en el ámbito universitario.

Ahora bien, en el mapa estudiantil platense de 1955 observaremos no solo corrientes reformistas sino también cristianas. En cuanto a la composición del reformismo, entre 1955 y 1956 encontramos un mapa estudiantil que se mantenía conducido por la alianza entre la UCR y grupos socialistas, anarquistas y trotskistas. Lo que la mantenía unida era tanto su ferviente antiperonismo como su anticomunismo, traducido este en el propósito de hacer frente en los Centros de Estudiantes a los grupos ligados al PC, generalmente minoritarios por causa de los sucesos de 1952. Como en la etapa previa, la fuerza de aquella alianza se expresaba en Facultades clave como Derecho, Ingeniería y Medicina, y tanto en la FULP como en la delegación platense a la FUA. Luego, la primera organización cristiana a considerar es el Movimiento Humanista. A diferencia de su par porteño, este grupo surgió recién en noviembre de 1955 con un comunicado donde expresó que participaría de las elecciones en los Centros adheridos a FULP. Por otro lado, en octubre de 1955 surgió la Federación Universitaria de Estudiantes Libres (FUEL), 


\section{El movimiento estudiantil de La Plata en los años '50: reformismo, peronismo y Guerra Fría a través de una década}

mucho más fuerte que el Humanismo y más extrema en sus posturas. La FUEL vendría a posicionarse como una organización cristiana antirreformista y anticomunista, con dos corrientes en su seno: una demócrata cristiana (que incluía militantes del Partido Demócrata Cristiano) y otra nacionalista católica, que acabará predominando con el correr de la década.

Comenzando el año 1956, tres hechos comienzan a agrietar aquel escenario: la sanción del Decreto-Ley no 6.043/55 y sus consecuencias; los movimientos políticopartidarios en la UCR, espacio de referencia para buena parte de nuestra militancia reformista; y un contexto social marcado por la movilización obrera contra las políticas económicas y represivas del gobierno de Aramburu. El primer suceso realmente cuestionado por los reformistas fue la sanción del Decreto-Ley n.o 6.043/55, en particular, su carácter de “inconsulto” y su Artículo n.28 que permitía a las universidades privadas emitir títulos habilitantes para el ejercicio profesional. Durante mayo de 1956, en lo que fue una suerte de primer episodio del conflicto "Laica o Libre", las universidades del país y un buen número de colegios secundarios protagonizaron un movimiento de protesta contra la normativa. En La Plata, los estudiantes ocuparon seis colegios secundarios, el Rectorado, ocho facultades y fue establecida en la UNLP una Junta de Gobierno estudiantil. El conflicto tuvo como desenlace la no aprobación del Artículo y la renuncia del ministro de Educación que lo promovió. Pero además, una fuerte crisis marcó al movimiento universitario platense, pues las protestas contra la normativa acabaron enfrentando a reformistas entre sí por los métodos utilizados para definir las acciones de la FULP. Esta cuestión, que hacía al debate en torno a la democracia interna, provocó renuncias, una intervención de la FUA por sobre la FULP de 60 días y un proceso eleccionario en todos sus Centros.

Pero este proceso intra reformista hizo de traducción de otro más bien políticopartidario, y por ende nacional, como fue el surgimiento de un ala de la UCR bajo el liderazgo de Arturo Frondizi y el alineamiento de grupos universitarios con dicha propuesta. Es que, si para 1955 y comienzos de 1956 encontramos un mapa estudiantil dominado por una alianza entre grupos compuestos por militantes o adherentes a la UCR, al socialismo y anarquismo, ya mediando 1956 este esquema se quiebra. Particularmente, las agrupaciones con militancia radical van a partirse en dos, emulando las líneas internas que desembocaron en la fractura del partido entre la UCR Intransigente (UCRI) y la UCR del Pueblo (UCRP). En esta suerte de crisis interna se observará una divergencia cada vez más clara en el seno del reformismo entre quienes, van a distanciarse de las posiciones iniciales y quienes no realizarán revisión de ningún tipo. Estos serán calificados como reformismo "democrático" o "auténtico", pues no cuestionaban las posiciones asumidas en 1955 además de que, proponían una no intromisión de elementos políticos en ellas. Mientras los reformistas ligados a la UCRP van a continuar encabezando la corriente autodenominada "democrática", junto a anarquistas y socialistas; los simpatizantes del frondizismo van a conformar una coalición con comunistas e independientes de izquierda, que va a dirigir la política estudiantil platense entre 1956 y 1959/1960. 


\section{Nayla Pis Diez}

De alguna manera, estamos frente a un primer episodio de ruptura de consensos, de renovación y desplazamientos en el seno del reformismo. El año 1957 es el de la consolidación de dicho espacio, en sus acciones públicas y en sus triunfos electorales, llegando además a conducir la FULP.

Un episodio clave para observar aquellas divergencias fue el II Congreso Latinoamericano de Estudiantes, realizado en La Plata, durante los últimos días de abril de 1957. El Congreso, organizado por la FUA y preparado por una comisión especial de la FULP, se trató de un encuentro masivo de jóvenes universitarios del continente y todo un acontecimiento para la ciudad marcando, especialmente, la rutina de la comunidad universitaria. Encuentra Laura Rodríguez (2018) que al final del Congreso se resolvió luchar contra las dictaduras de América Latina (a excepción de la argentina) y el imperialismo norteamericano; condenar el militarismo; denunciar la acción de la oligarquía y el clericalismo; protestar contra el Pacto del Atlántico Sur y la Junta Interamericana de Defensa. En relación al colonialismo, apoyar la lucha por la independencia de los pueblos de las Guayanas, Jamaica y Puerto Rico; y expresar la más amplia solidaridad por los movimientos en Malasia, Argelia, Chipre, Madagascar y África Negra. Sobre la situación en Europa, decidieron condenar la dictadura franquista en España y la invasión soviética a Hungría. Por último, abrogaron por sostener una vinculación permanente entre el movimiento estudiantil y el obrero. Este último punto habría suscitado algunas discrepancias pues suponía romper con la intransigencia antiperonista del movimiento estudiantil local (Rodríguez, 2018, p.104). Sin embargo, sus consecuencias no fueron del todo positivas para el mapa estudiantil platense pues suscitó cuestionamientos concretos a la gestión de FULP que desnudaba fuertes diferencias intra reformistas en torno a la politización del movimiento estudiantil y la universidad.

Ya un día antes que comience el Congreso, la cristiana FUEL emitió un comunicado repudiando su realización. Por un lado, denunciaba el apoyo que las autoridades universitarias prestaron al evento. Para ella, dicha participación comprometía ideológicamente a la universidad argentina pues (he aquí la segunda crítica) su carácter "primordialmente político" desvirtuaba la "esencia de todo sano gremialismo universitario" (El Argentino, 21/04/1957). Las acusaciones de este organismo deben comprenderse en un marco de Guerra Fría dado por el hecho de que, como comenta Claudio Arca (2006), buena parte de la opinión pública del continente acusaba al Congreso de responder a directivas comunistas. No obstante esto, la denuncia de FUEL no sería de relevancia si no fuera porque en el seno del reformismo aparecieron similares discrepancias. Miembros de la Junta Representativa de FULP (del sector reformista "democrático") realizaron hacia la conducción dos tipos de acusaciones: por un lado, se afirmaba que era un espacio dirigido por partidos políticos; segundo, se achacó a la dirigencia de la FULP el abandono de la "posición tercerista", es decir, igualmente distanciada de los imperialismos norteamericano y comunista, al encontrar que se habían silenciado críticas a la Unión Soviética. La postura crítica perdió la votación por el escaso margen de 44 votos a 38, por lo cual la dirigencia de FULP fue de alguna manera 


\section{El movimiento estudiantil de La Plata en los años '50: reformismo, peronismo y Guerra Fría a través de una década}

refrendada. Tal como sostiene Rodríguez (2018), nos sirve este evento para ilustrar cómo la discusión pública, universitaria y estudiantil, se encontraba atravesada por expresiones y acusaciones de pertenencia al comunismo, al imperialismo norteamericano, y a todo tipo de totalitarismos, resultando parte del "sentido común de los actores" explicitar de qué lado del mundo bipolar se estaba.

Luego del Congreso siguieron dos líneas de acción que profundizaron las diferencias: por un lado, acciones contra el Pacto de Defensa del Atlántico Sur y un paro en repudio al cubano Fulgencio Batista que finalmente fue suspendido por un no acuerdo en FULP; por otro, diversas acciones con sectores del movimiento obrero de la ciudad, entre ellos un acto por el Primero de Mayo de 1957, también con desacuerdos en FULP en torno a su tono partidario y alejado del plano gremial Más concretamente, podemos decir que el no permanecer en el "adentro" universitario se convirtió en una de las causas de debate y fragmentación del reformismo platense. Los cuestionamientos a la "renovada" FULP radicaron justamente en las acciones, las declaraciones y los procedimientos que se utilizaron en los primeros meses de 1957 dominados por el antiimperialismo, la solidaridad con el pueblo cubano y con un movimiento obrero perseguido. Como vemos, en principio, ninguno de ellos contradice las banderas clásicas de la Reforma, el punto en debate fue tanto su contundencia como la dirección que expresaban en el marco de la coyuntura política argentina: cuánto expresar y comprometer a los gremios en tales empresas, a qué sindicatos acercarse, qué decir de las dictaduras latinoamericanas (atravesando el país una dictadura militar), qué decir de los papeles de Estados Unidos y la Unión Soviética en los conflictos mundiales, aparecieron como puntos de desencuentro y fragmentación reformista. Era la disputa, en definitiva, en torno a cómo interpretar y cómo dar concreción a los principios de la Reforma.

\section{El reformismo frente al proyecto de Frondizi: ilusión, traición y nuevas coordenadas (1958-1960)}

La llegada a la presidencia de Arturo Frondizi cierra un episodio para los estudiantes reformistas, al tiempo que abre otro, más bien marcado por su "traición" y la radicalización de las posturas de quienes lo habían apoyado. Como han afirmado importantes estudios, su campaña electoral, primero, y luego su victoria en febrero de 1958, generaron hondas expectativas en intelectuales, profesionales y estudiantes cercanos al mundo de la izquierda pero atravesados por una suerte de crisis política e ideológica. Según los trabajos de Sigal (1991) y Carlos Altamirano (2001) dicha crisis encontró expresión en una suerte de fractura generacional en los mayores partidos, que incluyó una "situación revisionista" respecto del fenómeno peronista, caracterizada tanto por un proceso de "autoculpabilización" como también por grietas en las posturas antiperonistas de los jóvenes universitarios, intelectuales y militantes de izquierda y radicales. El frondizismo, expuesto como frente "nacional y popular", y su propuesta de "integración" hacia el movimiento 


\section{Nayla Pis Diez}

obrero peronista, colaboraron con la resolución política de dicha crisis. El campo de la militancia estudiantil reformista no quedó exento de esta reorientación política aunque la atravesó con sus particularidades. Una expresión concreta de tal proceso se encuentra en el hecho de que, entre fines de 1956 y comienzos de 1958, el ascenso de agrupaciones ubicadas en un reformismo "renovado" y de izquierdas, aparece como dato. Como se adelantó en el apartado anterior, el ascenso de esta corriente política cristaliza en el seno del mapa estudiantil de la UNLP el primer episodio de renovación reformista de la etapa posperonista, dado por un nuevo tipo de discurso, menos antiperonista y crítico de la Revolución Libertadora. Por un lado, tales críticas se centraban en la pérdida de derechos sociales y en la política represiva aplicada sobre el movimiento obrero. Por otro lado, el latinoamericanismo, un principio clásico del reformismo que, abandonado durante la década anterior frente a posicionamientos internacionales de corte antifascista, comenzó a adquirir un contenido concreto antiimperialista y, más concreto aún, crítico hacia la política estadounidense en la región. Por último, este sector reformista va a iniciar una suerte de abandono de las posturas más anticomunistas, también heredadas de la década anterior. Las críticas hacia el gobierno militar, la expectativa depositada en la figura de Frondizi, las revisiones y la "tolerancia" respecto del peronismo se exponen como procesos que encontraron a los jóvenes comunistas con aquellos radicales ahora frondizistas.

El "frondizismo universitario" se mantuvo y creció en coalición con la militancia comunista y núcleos independientes, sin filiación partidaria pero cercanos a la propuesta política del espacio. Los grupos que encabezaron este proceso tuvieron un peso mayoritario en Derecho, Ingeniería y Económicas, las facultades con mayor población. Algunos de sus referentes más importantes, para este año y el siguiente, fueron Alejandro Dabat, Ramón Torres Molina y Julio Godio. Por su parte, el llamado reformismo "democrático" mostraba una posición cuyos elementos centrales se entienden casi en espejo con las características de otro bloque, estas son: una suerte de apoliticismo, con fuertes críticas al otro bloque por "partidizar" las cuestiones universitarias, acompañado de un persistente antiperonismo y posiciones críticas hacia la Unión Soviética.

En la segunda mitad de 1958, comienzan a cambiar las cosas a partir de los conflictos suscitados en torno al Artículo n.ำ28, a la llamada Batalla del Petróleo y al conjunto de medidas que acabaron conocidas como parte de la "traición Frondizi". Tanto en La Plata como en el país, la oposición a la realización de acuerdos con capitales extranjeros para la explotación del petróleo, como a la posibilidad de que las universidades privadas lograran la potestad de emitir títulos habilitantes, crearon un clima de movilización y oposición que marcó los meses que van de junio a octubre de 1958. Los temas del estudiantado comenzaron a articularse a partir de una lectura que ubicaba temas propios del campo universitario (el "limitacionismo", el elitismo o la creación de universidades privadas) en un contexto más general de oposición a lo que se entendía como la "entrega del país" y el "avance de fuerzas reaccionarias", el clero, la oligarquía y el imperialismo. La voz que principalmente 


\section{El movimiento estudiantil de La Plata en los años '50: reformismo, peronismo y Guerra Fría a través de una década}

representaba este discurso era, claro, la de una FULP conducida por el reformismo de izquierdas. Además de sostener ese discurso, de realizar por casi dos meses acciones sucesivas y violentas en las calles de la ciudad, la orientación de la FULP incluyó también un intento de mayor acercamiento al movimiento obrero, sobre todo a sus dirigencias (peronistas). Con mayor o menor éxito, esto tuvo una nota de color en octubre de 1958, cuando la dirigencia estudiantil y el presidente de FULP (Carlos Schiavello) ofrecieron los jardines de la UNLP para la apertura de un plenario regional de la CGT que había sido prohibido. El mismo no se realizó pero la osada propuesta provocó un fuerte enfrentamiento al interior mismo del reformismo y a raíz de la oposición de algunos "auténticos" de Derecho.

A comienzos de 1959, las agrupaciones frondizistas entraron en una suerte de crisis política y electoral, que se materializó en experiencias, individuales y grupales, de radicalización hacia la izquierda. Estas se vieron acompañadas de fuertes críticas a la UCRI gobernante, al reformismo universitario así como también a las formas de funcionar que la política argentina había asumido de 1955 en adelante. En concreto, estamos frente a un nuevo episodio de desplazamientos en el cual las trayectorias de los "decepcionados" se inclinaron por caminos más radicalizados y pasaron optaron por dos caminos. Por un lado, el ingreso a la trotskista Palabra Obrera, que al comienzo supuso un abandono del espacio universitario y la "proletarización" de quienes la integraban; por otro, el armado en la ciudad del Movimiento de Izquierda Revolucionaria-Praxis, organización liderada por Silvio Frondizi, hermano del presidente. En este caso, el grupo sí mantuvo un pie en la UNLP (con presencia en Derecho, Humanidades y Medicina), al tiempo que ganó cierto espacio en la ciudad, con algunas decenas de militantes, la referencia de S. Frondizi y diversas actividades en torno a Cuba.

Este cuadro de crisis tiene expresión en un ámbito más: el IV Congreso de FUA, el primero después de sucedida la Revolución Libertadora (el III Congreso data del año 1942). Este iba a realizarse en La Plata en junio de 1959 sino fuera porque acabó frustrado por divergencias en la FULP: bajo el argumento de la nulidad de los estatutos del gremio y el escaso tiempo de convocatoria del evento, un sector del reformismo platense impugnó la realización del Congreso. Particularmente, el sector "auténtico" se mostró contrario al acontecimiento frente a un reformismo de izquierdas ahora, y tras el repliegue del frondizismo, hegemonizado por el comunismo que conducía la FULP desde marzo de 1959. Cuando el Congreso logre realizarse, en octubre de 1959 en Córdoba, una fracción de la delegación platense se retiró del encuentro. De la misma manera lo hicieron los delegados de Línea Recta de Ingeniería de la UBA, algunos de Litoral y Córdoba y los Humanistas. En una declaración a posteriori, los grupos platenses van a denunciar la nulidad de los estatutos y el sistema de reparto de cargos, según ellos, uno propenso "al copamiento de las minorías, lo que efectivamente sucedió en Córdoba, donde militantes del PS (secretaría Muñiz), bolches y troskos, en "unión vergonzosa" se aseguraron la mayoría circunstancial" (El Argentino, 27/10/1959). Sigue a esto la fuerte pero nada nueva denuncia a aquellas organizaciones por utilizar el 
movimiento universitario como "instrumento al servicio de un partido". Finalmente, el Congreso elaboró un programa fuertemente antiimperialista, que repudiaba buena parte de las medidas del gobierno de Frondizi y declaraba su apoyo a la lucha de los trabajadores frente al Plan de Estabilización del gobierno (Ceballos, 1985, pp. 25 y ss.). En La Plata, las corrientes reformistas existentes van a ordenarse en dos líneas programáticas: una opositora al programa de la FUA, encabezada por los grupos del reformismo "auténtico"; una segunda corriente (llamada "línea FUA") conformada por las agrupaciones reformistas de izquierda, es decir, integradas centralmente por comunistas y ex frondizistas, que va a adherir al programa del IV Congreso. Esta división marcará al movimiento universitario platense hasta, por lo menos, el año 1966.

\section{Palabras Finales}

En principio, este trabajo se propuso realizar una lectura atenta y procesual a las formas de relacionarse con la política de una parte de la sociedad argentina, en un tiempo y lugar determinados: las organizaciones estudiantiles identificadas como reformistas, ubicadas en la ciudad de La Plata en la década de 1950. Estamos hablando de actores colectivos, organizados alrededor de un espacio (la universidad), una identidad política y una serie de banderas (las reformistas), tan históricas como cambiante su significado. Es que la heterogeneidad es el otro dato a resaltar y mucho quedaría por decir de esto si sólo atendemos a los cambios principales de ese espacio y esa identidad (su adentro); contrariamente, aquí propusimos una lectura que, considerando esas dos cuestiones, buscó tensarlas y complementarlas con los elementos políticos y partidarios que marcaron las coordenadas de la década. Desde aquí, se visualiza que la militancia estudiantil reformista era también política y partidaria, y no leía la realidad nacional solo desde su condición de estudiante. La manera como cada una de las agrupaciones y corrientes resolvía aquella tensión provocó importantes disidencias y no un "nosotros" reformista sino varios.

Para 1955, el reformismo mayoritario en la UNLP era, como en buena parte del país, uno profundamente defensor de aquel "consenso" antiperonista, en buena medida, por una posición que articuló razones universitarias (el modelo peronista era uno casi opuesto al reformista), gremiales (la actividad de los Centros estaba realmente prohibida) y políticas; en este último punto, el antiperonismo bien empalmó con un discurso anticomunista y opositor a "los totalitarismos". El año 1955 constituye un punto de inflexión tanto para la política del país como para la historia del movimiento estudiantil. Si bien hacia el cierre del año y comienzos del siguiente aún predominaba aquel "consenso", mediando 1956 ubicamos un primer momento de desplazamientos que tuvo como nota central la ruptura de ese movimiento estudiantil antes contenido en esas coordenadas ideológicas. Y aquí también se entremezclan factores, pues a la decisión gubernamental de aprobar una normativa universitaria sin consulta al estudiantado ocurrió más o menos en simultáneo con la 


\section{El movimiento estudiantil de La Plata en los años '50: reformismo, peronismo y Guerra Fría a través de una década}

crisis del "consenso antiperonista" en importantes actores del campo político y social con los cuales el estudiantado compartía ese consenso, la UCR y sectores del movimiento obrero. Dicho quiebre no hizo más que evidenciar el surgimiento de un nuevo espacio y una nueva forma de politización: el "frondizismo universitario", que aparecía en correspondencia con las disidencias internas que atravesaron la UCR. Este, a su vez, se convirtió en cabeza de una suerte de corriente reformista de izquierdas, que comenzó a actuar en alianza con un comunismo hasta entonces desprestigiado por su posición "tolerante" respecto del gobierno peronista. Los grupos que conformaron esta corriente se posicionaron, sin dudas, en una nueva posición respecto de los pares que marcaron la década: peronismo/antiperonismo y comunismo/anticomunismo, redefiniendo como vimos una buena parte de las banderas reformistas en función de ello.

\section{Bibliografía}

Acha, 0. (2011) Los muchachos peronistas. Orígenes olvidados de la Juventud Peronista (1945-1955). Buenos Aires: Sudamericana.

Altamirano, C. (2001) Peronismo y cultura de izquierda. Buenos Aires: Temas.

Andrade, M. (2007) "Para una historia del maoísmo argentino", entrevista a Otto Vargas. Programa de Historia Oral de la Facultad de Filosofía y Letras de la UBA. Buenos Aires: Imago Mundi.

Arca, C. (2006) El Segundo Congreso Latinoamericano de Estudiantes. En Biagini H. y Roig A. (dir.) El pensamiento alternativo en la Argentina del siglo XX, Tomo II. Buenos Aires: Biblos.

Buchbinder, P. (2005) Historia de las universidades argentinas. Buenos Aires: Sudamericana.

Califa, J. S. (2014) Reforma y Revolución. La radicalización política del movimiento estudiantil de la UBA 1943-1966. Buenos Aires: Eudeba.

Camarero, H. (2013) El período formativo de un intelectual: Milcíades Peña y el trotskismo en las décadas de 1940-1950. Revista Archivos de historia del movimiento obrero y la izquierda (3).

Camarero, H. (2014) Tras las huellas de una ilusión: el PC argentino y sus planteos del Frente Democrático Nacional (1955-1963). Revista Archivos de historia del movimiento obrero y la izquierda (5). 


\section{Nayla Pis Diez}

Ceballos C. (1985) Los estudiantes universitarios y la política 1955-1970. Buenos Aires: CEAL.

Ferrero, R. (2009) Historia Crítica del Movimiento Estudiantil de Córdoba. Tomo III (1955-1973). Córdoba: Alción.

Franco, M. (2019) En busca de la "guerra fría". Culturas políticas, procesos locales y circulaciones de largo plazo. Prismas (23).

Galván, V. (2018). El anticomunismo transnacional en la Argentina durante las presidencias de Lonardi y Aramburu: vínculos y ejes interpretativos. En Osuna M. y Galván V. (comps.) La Revolución Libertadora en el marco de la Guerra Fría. Rosario: Prohistoria.

Graciano, 0. (2005) La universidad argentina durante los primeros gobiernos peronistas (1945-1955). En Girbal Blacha N., et al. Perfiles históricos de la Argentina peronista (1946-1955). La Plata: Al margen.

Graciarena, J. (1971) Clases medias y movimiento estudiantil. El Reformismo Argentino: 1918-1966. Revista Mexicana de Sociología (1).

Janello, K. (2013) Las políticas culturales del socialismo argentino bajo la Guerra fría. Las redes editoriales socialistas y el Congreso por la Libertad de la Cultura. Papeles de Trabajo (12).

Kleiner, B. (1964) 20 años de Movimiento Estudiantil Reformista (1943-63). Buenos Aires: Platina.

Marchesi, A. (2017) Escrevendo a Guerra Fria latinoamericana: entre o Sul 'local' e do Norte 'global. Revista do Estudos Históricos (60).

Millán, M. (2018) Un análisis crítico de las interpretaciones sobre los movimientos estudiantiles de los '60. En Bonavena y Millán (eds.) Los '68 latinoamericanos: movimientos estudiantiles, política y cultura en México, Brasil, Uruguay, Chile, Argentina y Colombia. Buenos Aires: IIGG-CLACSO.

Panella, C. (2014) Actitud: publicación de lucha e incitación política en tiempos del primer peronismo. En Panella y Korn (comps.) Ideas y debates para la nueva Argentina: revistas culturales y políticas del peronismo. La Plata: EPC.

Petra, A. (2013) Cultura Comunista y Guerra Fría: los intelectuales y el movimiento por la paz en la Argentina. Cuadernos de historia (38). Recuperado de: https://scielo.conicyt.cl/scielo.php?script=sci arttext\&pid=S0719$\underline{12432013000100004}$

Portantiero, J. C. (1978) Estudiantes y política en América Latina. México: Siglo XXI. 


\section{El movimiento estudiantil de La Plata en los años '50: reformismo, peronismo y Guerra Fría a través de una década}

Pis Diez, N. (2018) Universidad, política y radicalización en el posperonismo : el caso de la Universidad Nacional de La Plata y su movimiento estudiantil reformista (1955-1966) (Tesis doctoral)._UNLP, La Plata._Recuperado de: http://www.memoria.fahce.unlp.edu.ar/tesis/te.1678/te.1678.pdf

Pis Diez, N. (2019) La supresión de los aranceles universitarios en Argentina (1949/1952/1954). Posiciones y oposiciones en torno a una pieza clave del "modelo peronista de universidad". En Benente, M. (coord.) "Donde antes estaba solamente admitido el oligarca". La gratuidad de la enseñanza superior, a 70 años. Buenos Aires: EDUNPAZ

Pronko, M. (2000) El peronismo en la universidad. Buenos Aires: Libros del Rojas.

Rey Tristán, E. (2012) Estados Unidos y América Latina durante la Guerra Fría: la dimensión cultural. En Benedetta, C. y Franco, M. (comps.); La guerra fría cultural en América Latina. Desafíos y límites para una nueva mirada de las relaciones interamericanas. Buenos Aires: Biblos.

Rodríguez, L. (2018) Educación y universidad en los años de la "Libertadora". Redes trasnacionales y Guerra Fría cultural. En Osuna M. y Galván V. (comps.) La Revolución Libertadora en el marco de la Guerra Fría. Rosario: Prohistoria.

Sigal, S. (1991) Intelectuales y poder en la década del sesenta. Buenos Aires. Puntosur.

Spinelli, M.E. (2005) Los vencedores vencidos. El antiperonismo y la "Revolución Libertadora". Buenos Aires: Biblós.

Toer, M. (1988) El movimiento estudiantil de Perón a Alfonsín, Buenos Aires: CEAL.

Tortti, M. C. (2018) Liberales, socialdemócratas e izquierdistas en el PS durante la "Revolución Libertadora". En Osuna M. y Galván V. (comps.) La Revolución Libertadora en el marco de la Guerra Fría. Rosario: Prohistoria.

Recibido: $25 / 01 / 2020$

Evaluado: 26/02/2020

Versión Final: 15/03/2020 